\title{
DETEKSI CACAT UBIN KERAMIK MENGGUNAKAN TEKNIK PENGOLAHAN CITRA DAN ADAPTIVE NEURAL FUZZY INFERENCE SYSTEM (ANFIS)
}

\author{
Andri \\ Program Studi Teknik Informatika, Universitas Indraprasta PGRI \\ Email: andriecitra@gmail.com
}

\begin{abstract}
Abstrak
Pada produksi massal, sistem inspeksi visual telah digunakan untuk meningkatakan produk yang berkualitas tinggi. Hal ini didorong oleh fakta bahwa industri manufaktur sangat termotivasi untuk menggunakan sistem pemeriksaan yang membutuhkan keakuratan tinggi dengan instalasi dan biaya pemeliharaan yang rendah. Penelitian ini untuk meningkatkan klasifikasi produk pabrik keramik yang berhubungan dengan pendeteksian cacat dengan mengacu pada model sistem inspeksi, menggunakan ubin keramik. Banyak penelitian tentang pengujian ubin keramik yang sudah dilakukan, tetapi masih banyak yang belum memberikan hasil yang optimal dan masih ditemukan beberapa permasalahan dalam kenyataanya. Permasalahan yang timbul adalah waktu akses yang masih lambat, keakuratan data yang rendah dan tingkat kesalahan yang tinggi. Penelitian ini menggabungkan teknik pengolahan citra dan model Adaptive Neural Fuzzy Inference System (ANFIS). Hasil yang diperoleh dari penelitian ini adalah pengujian ubin keramik yang lebih akurat dibandingkan dengan penelitian sejenis yang pernah dilakukan. Berdasarkan hasil penelitian dan pengujian yang dilakukan, model ANFIS sangat layak dijadikan sebagai model inferensi kecerdasan buatan dalam sistem yang berbasis inspeksi otomatis khususnya dalam menemukan cacat pada ubin keramik. Hybrid trapesium mf yang digunakan pada model ANFIS memiliki kesalahan 0,172737 dan akurasi pengujian data adalah $99 \%$.
\end{abstract}

Kata kunci: Sistem Inspeksi Visual, pendeteksian cacat, pengolahan citra, Adaptive Neuro Fuzzy Inference dan Fuzzy Logic

\section{Pendahuluan}

Secara tradisional, inspeksi visual dan quality control dapat dilakukan oleh manusia secara manual. Pekerjaan ini lebih lambat jika dibandingkan dengan menggunakan mesin yang berbasis komputer. Dengan mesin berbasis komputer ini inspeksi visual dan quality control dapat dilakukan secara terus menerus dengan kualitas yang sama. Salah satu mesin yang berbasis komputer adalah Sistem VisualInspeksi Otomatis (AVIS) dimana biaya pemeliharaan lebih murah dan akurasi tinggi. latar belakang penelitian menggambarkan pentingnya menggunakan sistem visual inspeksi otomatis. Walaupun demikian beberapa industri keramik masih belum menggunakannya karena sistem visual inspeksi otomatis terlambat diperkenalkan sehingga masih menggunakan secara tradisional. Faktor yang menghambat penggunaan sistem visual inspeksi otomatis adalah : system ini tidaklah sederhana, kurangnya fleksibilitas dasar perancangan, kurangnya metoda kajian kinerja dan kurangnya studi kasus yang menghambat pengembangan inspeksi visual otomatis. Banyak penelitian dengan objek Ubin Keramik (Ceramic Tile) yang menggunakan Sistem Inspeksi Visual Otomatis yang telah dilakukan, tetapi dari penelitian - penelitian yang sudah dilakukan ada beberapa yang sudah memberikan hasil yang optimal dan ada juga yang belum optimal. Misalnya ada penelitian yang dari presentasi keakuratannya kecil, waktu akses yang masih lama, teknik pengolahan citra yang kurang tepat. Beberapa penelitian juga hanya mengandalkan teknik pengolahan citra belum dibantu dengan teknik kecerdasan buatan, sehingga berdampak pada keakuratan data yang diperoleh. 
Berdasarkan permasalahan di atas, penulis tertarik untuk melakukan penelitian dalam bidang pengujian kualitas Ubin Keramik dengan teknik dan model yang berbeda. Penelitian ini menggunakan teknik pengolahan citra dan model Adaptive Neural Fuzzy Inference System (ANFIS).

\section{Tujuan Penelitian}

Untuk mengklasifikasikan kualitas ubin keramik dengan cara:

a. Mengimplementasikan teknik pengolahan citra, dengan analisis citra yang digunakan meliputi skala keabuan, segmentasi, dan proses binerisasi sebagai input untuk proses pelatihan klasifikasi kualitas ubin keramik.

b. Mengembangkan Adaptive Neuro Fuzzy Inference System (ANFIS) sebagai model yang digunakan untuk mengklasifikasikan kualitas ubin keramik ke dalam kelompok good (G) dan $n o t \operatorname{good}(\mathrm{NG})$.

\section{Manfaat Penelitian}

a. Industri : supaya termotivasi untuk mengamankan produksi dengan instalasi dan biaya pemeliharaan yang murah. Metode yang diusulkan akan membantu perusahaan untuk menggunakan machine visual berbasis sistem untuk mengidentifikasi cacat tanpa menggunakan peralatan tambahan. Dengan kata lain, pelaksanaan biaya rendah akan mendorong pabrik-pabrik untuk membuat dan mengkategorikan produk mereka secara otomatis.

b. Peneliti : penelitian ini diharapkan menjadi model sistem, yang menggabungkan teknik pengolahan citra dan teknik Adaptive Neuro Fuzzy Inference System (ANFIS) yang memberikan nilai akurasi yang tinggi dalam menentukan kualitas ubin keramik.

c. Peneliti lainnya : Hasil penelitian ini diharapkan menjadi bahan masukan, sehingga sistem ini menjadi acuan dan prototype model Sistem Inspeksi Visual otomatis (AVIS) untuk para peneliti lainnya.

\section{Tinjauan Pustaka}

\section{Sistem Inspeksi Visual Otamatis (AVIS)}

Avis digunakan dalam lini produksi massal untuk mendeteksi cacat pada produk eksterior. Meskipun pelaksanaan sistem tersebut tergantung pada objek yang akan diperiksa, sistem ini terdiri iluminator, sensor pencitraan, pengolahan gambar yang terkait dengan mekanisme penanganan (Narayan, 2008). Inspeksi visual adalah metode umum dari kontrol kualitas, akuisisi data, dan analisis data. Inspeksi visual seperti yang digunakan dalam pemeliharaan fasilitas berarti inspeksi peralatan dan struktur menggunakan satu, beberapa atau semua indra manusia seperti penglihatan, sentuhan pendengaran, dan penciuman (Lin, 2011).

Inspeksi merupakan aktivitas untuk menguji produk, komponen, perakitan, material yang akan diproses agar sesuai dengan spesifikasi desain. Otomasi Inspeksi didefinisikan sebagai satu atau beberapa langkah prosedur inspeksi yang terotomasi (Johan, 2011).

\section{Struktur Pada AVIS}

Struktur dasar Sistem Inspeksi Visi Otomatis dalam ubin keramik (AVISC) produksi terdiri dari bagian penerangan, visi kamera, dan sebagian klasifikasi. Kamera di atas conveyor menangkap gambar keramik. Posisi kamera yang ditunjukkan pada Gambar 1. Fungsi penting dalam AVISC yang secara langsung mempengaruhi pengambilan keputusan adalah akuisisi citra. Sumber cahaya neon, halogen atau Light Emitting Dioda (LED) (Mathiassen, 2007; Hocenski, 2008; Hocenski, 2010), sedangkan penelitian terbaru menunjukkan bahwa dibandingkan dengan lampu neon dan halogen, suara dari foto yang diambil dengan lampu LED berkurang dan dengan 
demikian memberikan gambar lebih baik (Hocenski, 2010). Menangkap gambar dengan kebisingan yang minimum dan posisi yang benar adalah tujuan dari bagian ini.

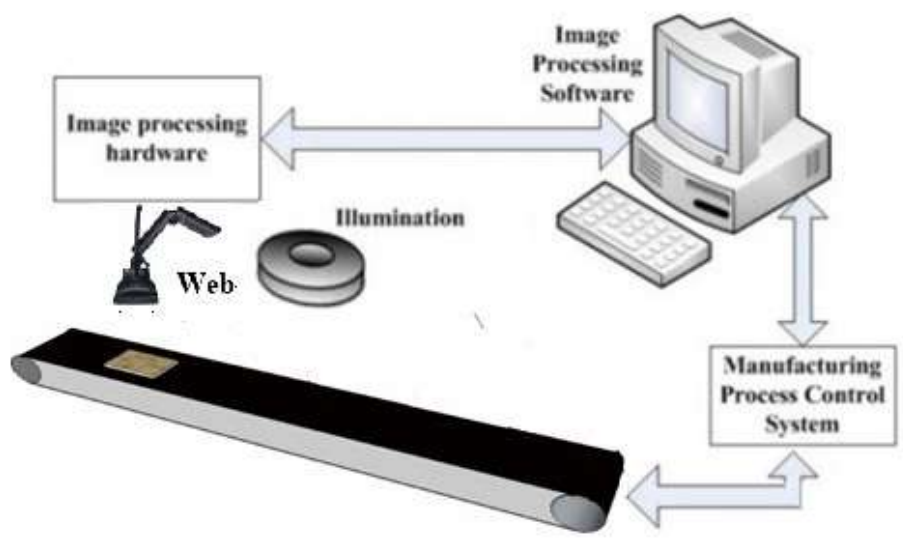

Gambar 1. Komponen Utama AVIS

\section{Metodologi Penelitian}

Dalam penelitian ini digunakan metode eksperimen. Eksperimen dalam penelitian ini adalah metode penelitian yang bertujuan untuk meneliti cacat ubin keramik dengan menggunakan metode Adaptive Neuro Fuzzy Inference System (ANFIS). Dengan metode ini ubin keramik yang akan dideteksi diambil imagenya. Kemudian image tersebut disimpan (save) di dalam hardisk computer. Dengan menggunakan matlab, database image di-upload dan dianalisis dengan Adaptive Neuro Fuzzy Inference System (ANFIS). Hasil analisis berupa cacat seperti crack, spot dan pecah pinggir. Dari cacat yang dihasilkan dan analisis dapat diketahui apakah ubin keramik tersebut baik atau tidak baik.

\section{Metode Pemilihan Sampel}

Sampel dalam penelitian diambil dari pabrik PT. Ubin Keramik Kemenangan Jaya (Klapa nunggal Cileungsi), sebanyak 28 buah ubin keramik. Sampel ini diambil image dengan menggunakan kamera digital agar hasil image tersebut dapat disimpan sebagai database dengan harapkan dapat diambil kapan saja dengan bantuan matlab.

\section{Metode Pengumpulan Data}

Dalam penelitian ini untuk mendapatkan data-data yang diperlukan penulis menggunakan beberapa metode pengumpulan data sebagai berikut :

1. Studi Pustaka

Merupakan teknik pengumpulan data dengan cara mempelajari referensi berupa dokumen/berkas dan mengumpulkan data yang berkaitan dengan ubin keramik yang baik dan tidak baik.

2. Observasi

Teknik pengumpulan data dengan melakukanpengamatan langsung.

\section{Instrumentasi}

Dalam penelitian ini instrumen yang digunakan untuk mendukung proses penelitian, terdiri dari dua bagian, yaitu :

Perangkat keras :

1. Kamera digital 12,2 mega pixel

2. Pencahayaan / LED 
3. Ubin keramiksebagai objek citra

Perangkat Lunak:

1. Sistem Operasi Windows Vista Basic Edition

2. Matlab versi $2010 \mathrm{~b}$

\section{Teknik Analisis Data}

Teknik analisis data yang digunakan adalah teknik Adaptive Neuro-Fuzzy Inference System (ANFIS). Alasan digunakan teknik atau model ini karena teknik ANFIS merupakan jaringan adaptif yang berbasis pada sistem kesimpulan fuzzy (fuzzy inference system). Dengan penggunaan suatu prosedur hybrid learning, ANFIS dapat membangun suatu mapping inputoutput yang keduanya berdasarkan pada pengetahuan manusia (pada bentuk aturan fuzzy if-then) dengan fungsi keanggotaan yang tepat.

Analisa data dilakukan dengan melakukan training terhadap data yang akan diuji. Teknik yang digunakan dalam menganalisa data uji Ubin keramik adalah teknik hybrid dan backpropagation, yang masing - masing menggunakan mf gaussian dan dan $\mathrm{mf}$ trapesium. Hasil analisa data dari model yang digunakan dibandingkan untuk mencari model mana yang paling baik dari sisi waktu proses, tingkat kesalahan, dan akurasi data.

\section{Hasil dan Pembahasan}

Proses Pengolahan Citra Ubin Keramik

Sistem inspeksi yang mengambil topik teknik pengolahan citra dan Adaptive Neuro Fuzzy System (ANFIS) untuk mendeteksi cacat Ubin keramik, dapat digambarkan sebagai berikut :

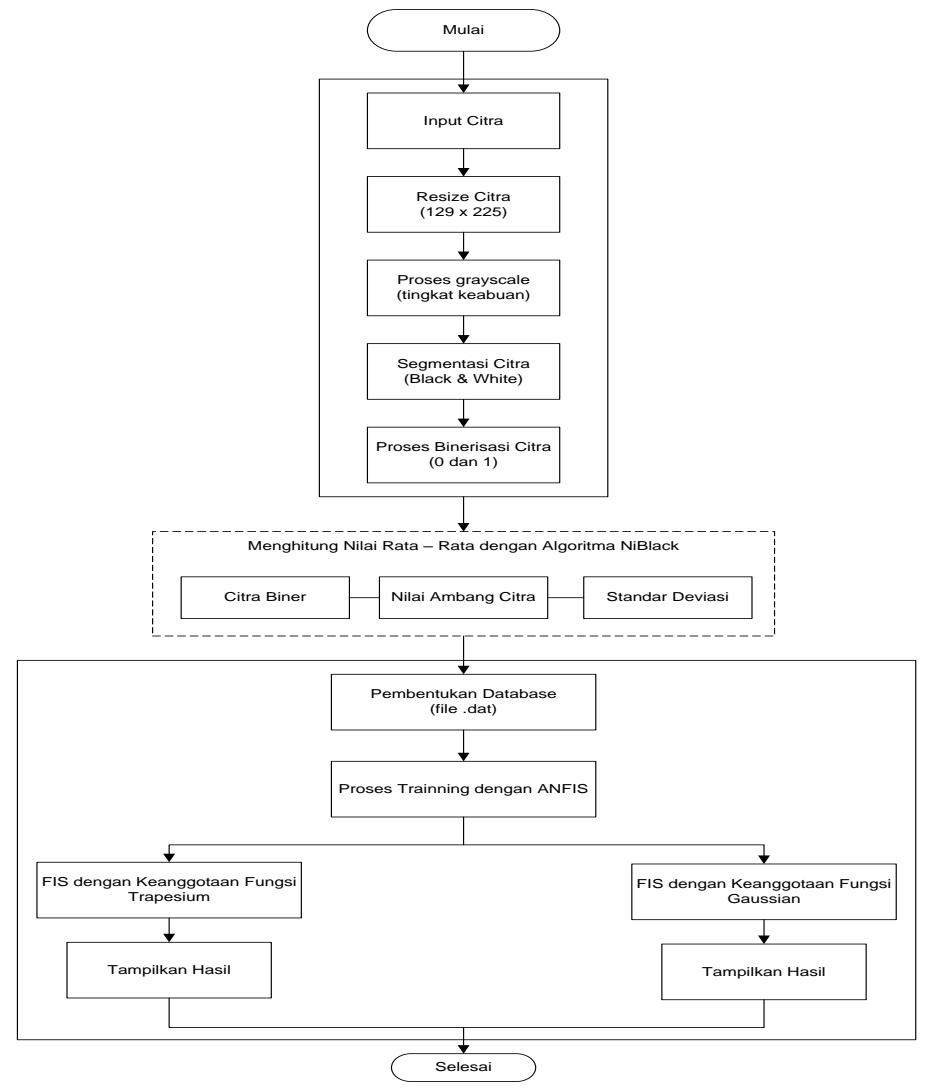

Gambar 2. Kerangka Pengembangan Sistem 
Dari gambar di atas, proses sistem terdiri dari dua tahapan, yaitu tahapan preprocessing yaitu pengolahan citra dan tahapan postprocessing proses inferensi dengan Adaptive Neural Fuzzy Inference System (ANFIS). Dari gambar kerangka pengembangan sistem, proses diawali dengan pembacaan data citra input berupa ubin keramik yang sudah disimpan dalam folder data citra hasil pengambilan citra statis menggunakan kamera digital. Proses selanjutnya ada operasi resize ukuran citra yang dilanjutkan dengan operasi keabuan citra (grayscale). Pengolahan citra berikutnya adalah segmentasi citra dengan konversi citra ke black and white (thresholding), dan selanjutnya melakukan operasi binerisasi. Tahap selanjutnya adalah mengolah hasil pengolahan citra, proses ini bertujuan untuk mendapatkan nilai ciri citra yang akan diolah, dimana nilai ciri citra ini diperoleh dengan mencari nilai rata - rata biner, nilai ambang, dan standar deviasi dengan menggunakan algoritma Niblack.

Untuk memperoleh citra hasil thresholding dapat menggunakan coding dalam matlab seperti di bawah ini :

\section{Proses Binerisasi}

Citra biner adalah citra yang memiliki dua nilai tingkat keabuan yaitu hitam dan putih. Dalam proses binerisasi ini, algoritma yang digunakan adalah algoritma Niblack. Secara umum proses binersisasi citra grayscale untuk menghasilkan citra biner adalah sebagai berikut:

\section{Proses Training Data}

Proses training data dilakukan dalam prototype sistem pengujian ubin keramik yang sudah diimplementasikan dengan menggunakan matlab versi 2010b dapat dilihat di bawah ini:

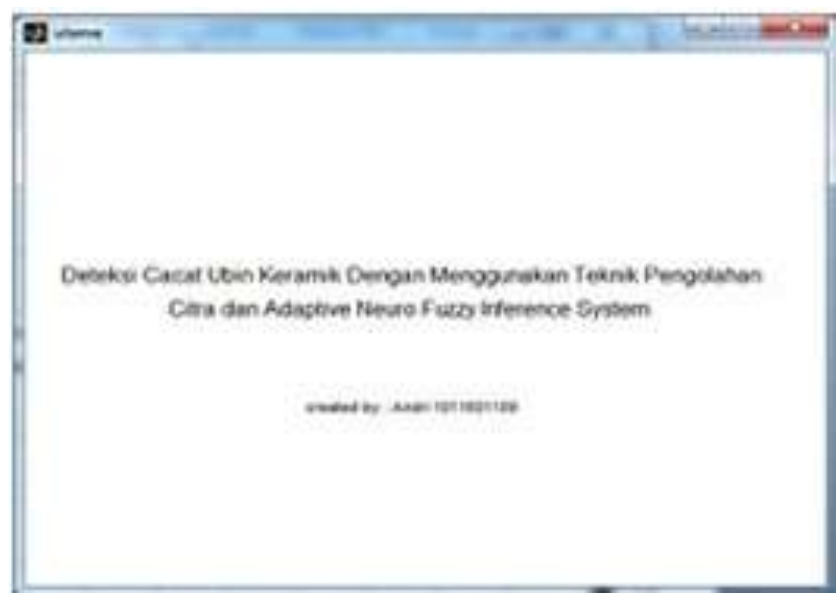

Gambar 3. Form Utama Sistem Yang Diimplementasikan 


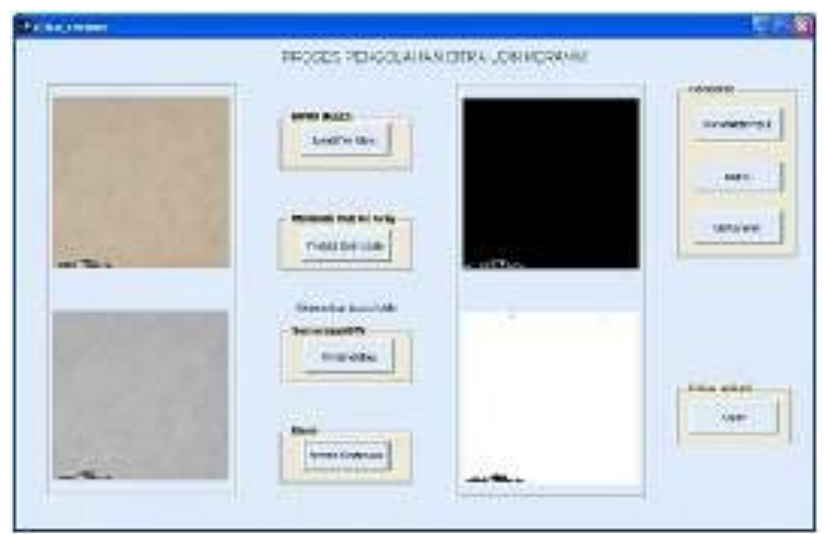

\section{Gambar 4. Form Proses Pengolahan Citra dan ANFIS}

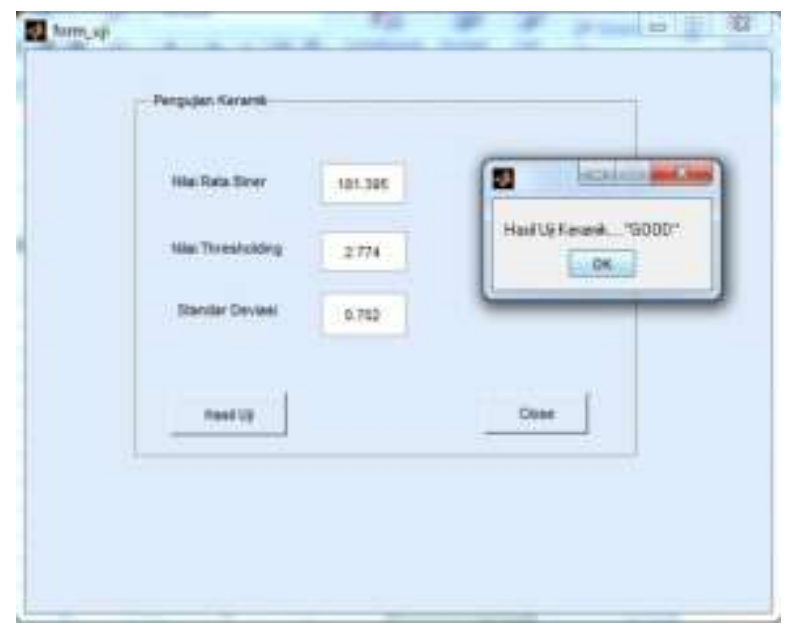

\section{Gambar 5. Form Pengujian ubin keramik}

\section{Proses Training ANFIS}

Pada proses ini training ini dipilih model Takagi-Sugeno dalam inferensinya, dimana output sistem tidak berupa himpunan fuzzy, melainkan berupa konstanta atau persamaan linier. Fuzzy inference system merupakan proses pemetaan dari suatu input ke output dengan menggunakan logika fuzzy yang dapat menyediakan dasar pengambilan keputusan atau pola yang diperoleh. Fuzzy inference system memiliki beberapa proses, yaitu proses Membership Function, Fuzzy Logic Operator, dan If Then Rule. Perancangan sistem fuzzy terdiri dari beberapatahapan yaitu :

1. Identifikasi karakteristik model secara fungsional dan operasional.

Pada tahapan ini menjelaskan karakteristik apa saja yang dimiliki oleh sistem yang ada serta merumuskan karakteristik operasi - operasi yang akan digunakan dalam model fuzzy. Pada sistem pengujian ubin keramik ini terdapat 3 input $\mathrm{mf}$ dan $1 \mathrm{mf}$ output. Input diperoleh dari rata - rata citra biner, nilai rata - rata grayscale, dan standar deviasi, sedangkan output yang terdapat dari sistem fuzzy adalah kualitas ubin keramik hasil identifikasi.

2. Membentuk membership function

Fuzzifikasi merupakan proses membuat suatu nilai crisp menjadi bersifat fuzzy. 
3. Membuat aturan fuzzy

Aturan ini menunjukkan bagaimana suatu sistem beroperasi. Sebagai contoh pembentukan aturan pada sistem inferensi fuzzy, akan dijelaskan cara pembentukan rule untuk kualitas ubin keramik yang baik (good). Aturan ini mempunyai tiga jenis masukan, yaitu rata - rata biner (r), ambang, dan standar deviasi. Bila fungsi keanggotaan kualitas ubin keramik berada pada himpunan yang sama maka rule yang digunakan untuk membentuk daerah fuzzy yang berhubungan dengan variabel solusi kualitas ubin keramik dapat diilustrasikan seperti if then rule seperti di bawah ini :

If(input1 is no_good) and (input 2 is good) and (input3 is cukup) then (output is no_good)

Berikut adalah tabel kelompok input untuk kualitas ubin keramik berdasarkan input yang diberikan :

Tabel 1. Kelompok Input dalam Kualitas ubin keramik

\begin{tabular}{lll}
\hline No & Nama Input & Variabel Input \\
\hline 1 & Input 1 & Rata-rata Biner \\
2 & Input 2 & Nilai Ambang citra (threshold) \\
3 & Input 3 & Standar deviasi \\
\hline
\end{tabular}

4. Menentukan metode defuzzyfikasi

Input dari defuzzyfikasi adalah suatu himpunan fuzzy yang diperoleh dari komposisi aturan aturan fuzzy, sedangkan output yang dihasilkan merupakan suatu bilangan pada domain himpunan fuzzy tersebut. Metode yang digunakan pada penelitian ini adalah metode centroid.

Pada sistem yang dibuat ini dipilih dua jenis tipe training, yaitu model hybrid dan backpropagation. Dimana pada masing - masing dari dua model ini akan menggunakan dua model mf, yaitu Gaussian dan Trapesium. Dua membership ini akan ditraining sebanyak 50 kali. Berikut cara pengaturan training dengan fungsi keanggotaan (mf) trapesium.

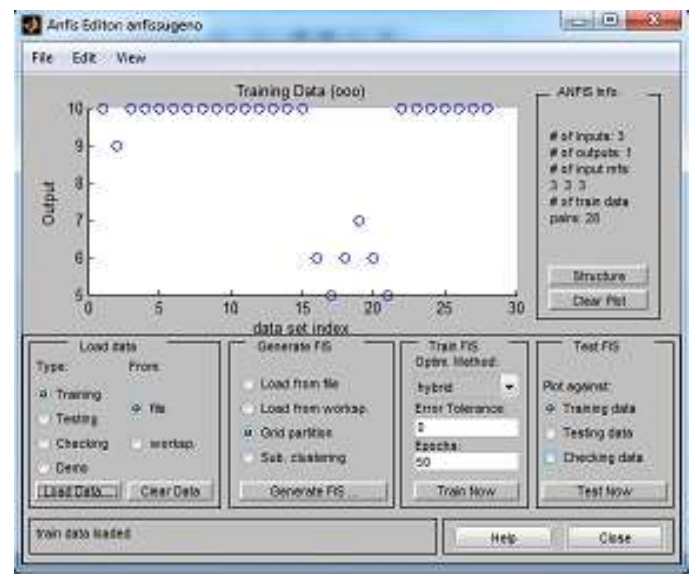

Gambar 6. Hasil Proses Training 


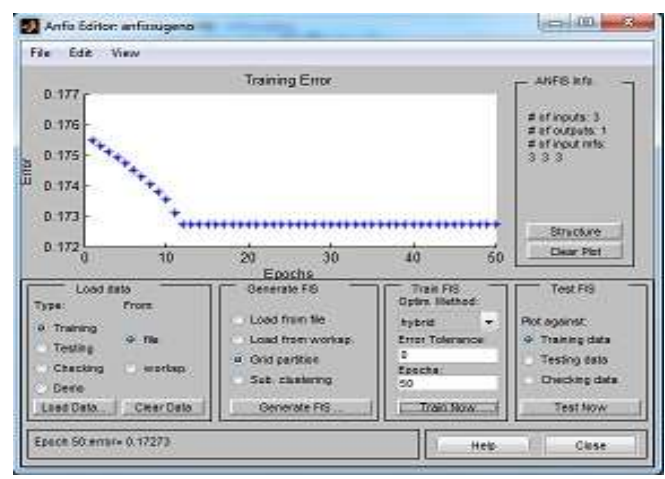

Gambar 7. Training Error dengan Hybrid Trapesium

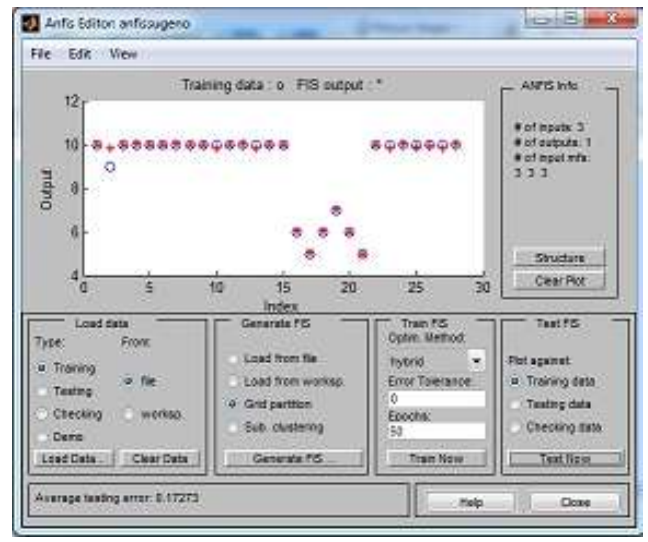

Gambar 8. Tingkat Rata - Rata Kesalahan Training Model Hybrid mf Trapesium

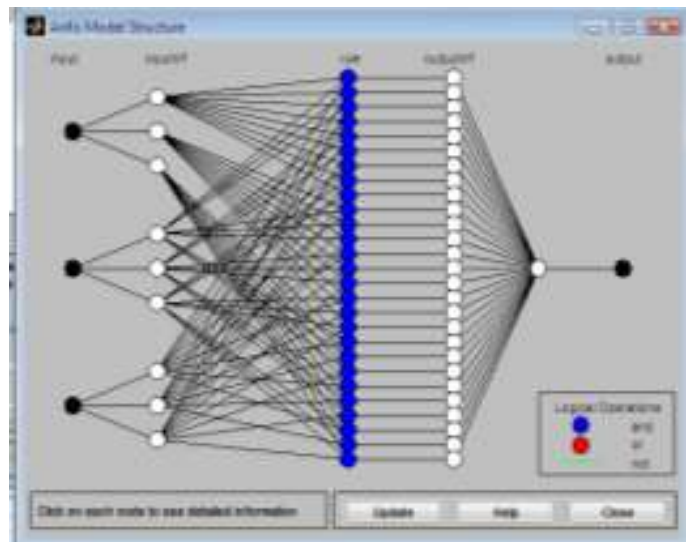

Gambar 9. Struktur ANFIS Yang Dihasilkan

Dalam proses training jumlah epoch mempengaruhi tingkat keakuratan data yang akan ditraining. Hasil proses training ini ditandai dengan diperolehnya nilai average testing error, dimana jika nilainya semakin kecil maka akan semakin baik proses pengenalannya terhadap data masukan. 


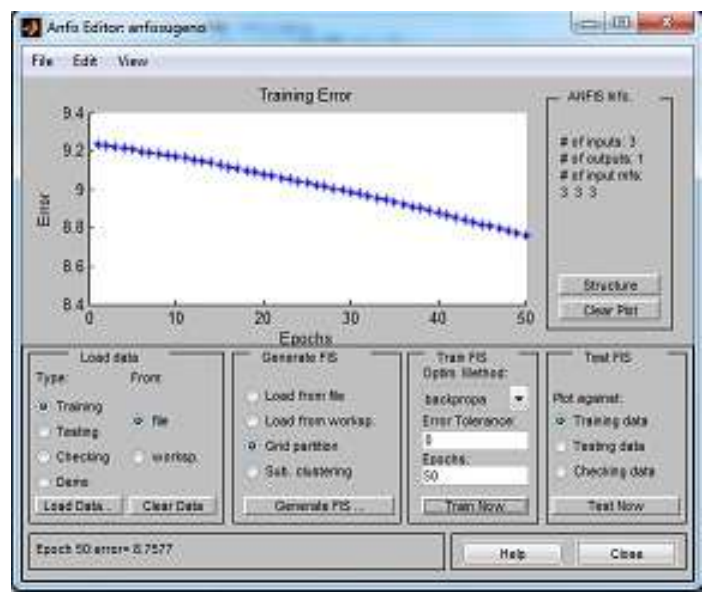

Gambar 10. Proses Training Error Model Backpropagation dengan mf Gaussian

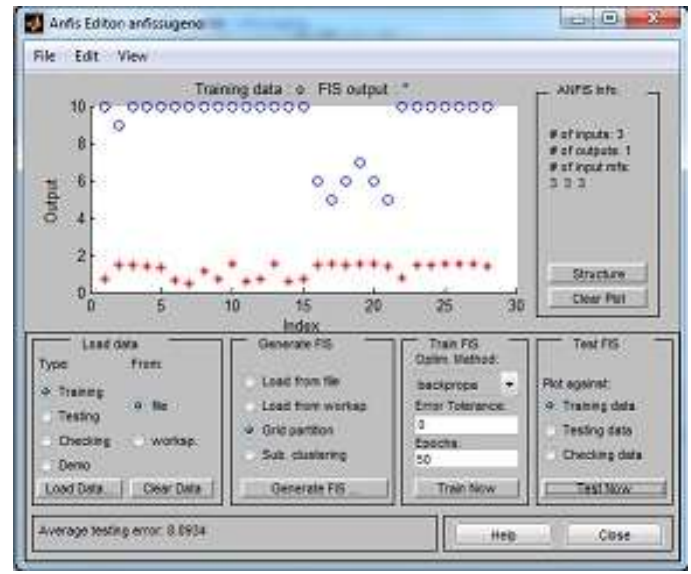

\section{Gambar 11. Tingkat Rata - Rata Kesalahan Pengujian dengan} Model Backpropagation mf Gaussian

Berikut adalah hasil pembentukan rule base deteksi kualitas ubin keramik dari database yang terbentuk dengan 3 jumlah input masing-masing mempunyai 3 kategori sehingga rule yang terbentuk dengan formula $\mathbf{n}^{\mathrm{i}}$, dimana nilai $\mathrm{n}=3$ dan $\mathrm{i}=3$, sehingga $3^{3}=27$ kombinasi.

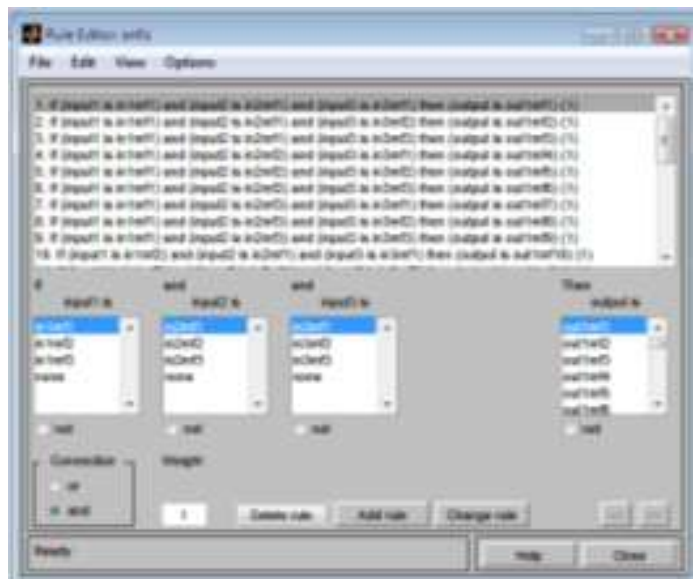

Gambar 12. Rule Editor yang Terbentuk dari 3 Input 


\section{Pengujian Sistem}

Proses pengujian hanya dilakukan terhadap model yang digunakan dalam penelitian ini yaitu Adaptive Neural Fuzzy Inference System. Hal ini sejalan dengan tujuan dari penelitian yaitu seberapa efektif dan akurat model ini digunakan. Pengujian dilakukan hanya pada proses training data dan pengujian data yang digunakan pada saat menguji ubin keramik. Pengujian dilakukan pada model hybrid dan backpropagation, sedangkan untuk implementasi sistemnya dibuat berdasarkan pada model yang paling baik tingkat akurasinya, yaitu model hybrid trapesium $m f$.

Pengujian sistem dilakukan pada 12 buah citra ubin keramik yang masing - masing sudah mempunyai nilai rata - rata citra biner, nilai standar deviasi, dan nilai ambang. Serta bobot nilai kualitas yang diberikan berdasarkan nilai terbaik dari ketiga variabel input citra. Di bawah ini adalah tabel data ubin keramik yang akan diuji.

Tabel. 2. Data Tabel Citra Ubin Keramik yang Diuji

\begin{tabular}{ccccc}
\hline No & Nilai Biner & $\begin{array}{c}\text { Nilai } \\
\text { Threshold }\end{array}$ & $\begin{array}{c}\text { Standar } \\
\text { Dev }\end{array}$ & $\begin{array}{c}\text { Nilai Kualitas } \\
\text { (bobot) }\end{array}$ \\
\hline 1 & 181.395 & 2.774 & 0.702 & 100 \\
2 & 178.195 & 3.026 & 0.698 & 100 \\
3 & 178.501 & 3.810 & 0.702 & 100 \\
4 & 181.900 & 2.231 & 0.702 & 100 \\
5 & 179.228 & 3.187 & 0.702 & 100 \\
6 & 181.923 & 2.251 & 0.702 & 100 \\
7 & 181.395 & 2.774 & 0.702 & 100 \\
8 & 178.195 & 3.026 & 0.576 & 60 \\
9 & 179.145 & 2.965 & 0.543 & 50 \\
10 & 178.208 & 2.683 & 0.569 & 60 \\
11 & 179.193 & 2.880 & 0.594 & 70 \\
12 & 178.659 & 3.001 & 0.567 & 60 \\
13 & 177.883 & 2.637 & 0.522 & 50 \\
\hline
\end{tabular}

Berikut ditampilkan perbandingan hasil proses training dan testing antara model hybrid dan backpropagation dengan masing - masing ditampilkan dengan fungsi keanggotaan mf trapesium dan mf gaussian.

Tabel 3. Perbandingan Nilai Tingkat Kesalahan Pada Proses Training

\begin{tabular}{|c|c|c|c|c|c|c|}
\hline \multirow[b]{2}{*}{ No } & \multirow[b]{2}{*}{$\begin{array}{l}\text { Nilai } \\
\text { Biner }\end{array}$} & \multirow[b]{2}{*}{$\begin{array}{c}\text { Nilai } \\
\text { Threshold }\end{array}$} & \multirow[b]{2}{*}{$\begin{array}{l}\text { Standar } \\
\text { Dev }\end{array}$} & \multirow[b]{2}{*}{$\begin{array}{c}\text { Nilai } \\
\text { Kualitas } \\
\text { (bobot) }\end{array}$} & \multicolumn{2}{|c|}{ Tingkat Akurasi } \\
\hline & & & & & $\begin{array}{c}\text { Hibrid } \\
\text { Trapesium } \\
\text { mf } \\
\end{array}$ & $\begin{array}{c}\text { Backpropagation } \\
\text { Trapesium mf }\end{array}$ \\
\hline 1 & 181.395 & 2.774 & 0.702 & 100 & 100.000 & 93.346 \\
\hline 2 & 178.195 & 3.026 & 0.698 & 90 & 98.349 & 91.256 \\
\hline 3 & 178.501 & 3.810 & 0.702 & 100 & 99.526 & 95.979 \\
\hline 4 & 181.900 & 2.231 & 0.702 & 100 & 100.000 & 95.846 \\
\hline 5 & 179.228 & 3.187 & 0.702 & 100 & 98.345 & 94.524 \\
\hline 6 & 181.923 & 2.251 & 0.702 & 100 & 100.000 & 93.346 \\
\hline 7 & 181.395 & 2.774 & 0.702 & 100 & 100.000 & 93.346 \\
\hline 8 & 178.195 & 3.026 & 0.576 & 60 & 60.041 & 52.245 \\
\hline 9 & 179.145 & 2.965 & 0.543 & 50 & 49.816 & 45.478 \\
\hline 10 & 178.208 & 2.683 & 0.569 & 60 & 56.233 & 52.867 \\
\hline 11 & 179.193 & 2.880 & 0.594 & 70 & 67.814 & 64.856 \\
\hline 12 & 178.659 & 3.001 & 0.567 & 60 & 59.801 & 51.475 \\
\hline 13 & 177.883 & 2.637 & 0.522 & 50 & 50.011 & 46.523 \\
\hline
\end{tabular}


Tabel 4. Perbandingan Nilai Tingkat Kesalahan pada Proses Testing

\begin{tabular}{|c|c|c|c|c|c|c|}
\hline \multirow[b]{2}{*}{ No } & \multirow[b]{2}{*}{$\begin{array}{l}\text { Nilai } \\
\text { Biner }\end{array}$} & \multirow[b]{2}{*}{$\begin{array}{c}\text { Nilai } \\
\text { Threshold }\end{array}$} & \multirow[b]{2}{*}{$\begin{array}{l}\text { Standar } \\
\text { Dev }\end{array}$} & \multirow[b]{2}{*}{$\begin{array}{c}\text { Nilai } \\
\text { Kualitas } \\
\text { (bobot) }\end{array}$} & \multicolumn{2}{|c|}{ Tingkat Akurasi } \\
\hline & & & & & $\begin{array}{c}\text { Hibrid } \\
\text { Trapesium } \\
m f\end{array}$ & $\begin{array}{c}\text { Backpropagation } \\
\text { Gaussian } m f\end{array}$ \\
\hline 1 & 181.395 & 2.774 & 0.702 & 100 & 100.000 & 95.846 \\
\hline 2 & 178.195 & 3.026 & 0.698 & 90 & 98.349 & 93.024 \\
\hline 3 & 178.501 & 3.810 & 0.702 & 100 & 99.526 & 94.797 \\
\hline 4 & 181.900 & 2.231 & 0.702 & 100 & 100.000 & 95.846 \\
\hline 5 & 179.228 & 3.187 & 0.702 & 100 & 98.345 & 93.024 \\
\hline 6 & 181.923 & 2.251 & 0.702 & 100 & 100.000 & 95.846 \\
\hline 7 & 181.395 & 2.774 & 0.702 & 100 & 100.000 & 95.846 \\
\hline 8 & 178.195 & 3.026 & 0.576 & 60 & 60.041 & 55.183 \\
\hline 9 & 179.145 & 2.965 & 0.543 & 50 & 49.816 & 44.183 \\
\hline 10 & 178.208 & 2.683 & 0.569 & 60 & 56.233 & 51.024 \\
\hline 11 & 179.193 & 2.880 & 0.594 & 70 & 67.814 & 62.809 \\
\hline 12 & 178.659 & 3.001 & 0.567 & 60 & 59.801 & 54.459 \\
\hline 13 & 177.883 & 2.637 & 0.522 & 50 & 50.011 & 45.024 \\
\hline
\end{tabular}

Dari kedua tabel di atas, dapat kita lihat bahwa model Hybrid baik itu fungsi keanggotaan ( $m f$ ) trapesium maupun gaussian memiliki tingkat kesalahan yang kecil pada saat melakukan training data.

Dari tabel perbandingan hasil pengujian antara hybrid trapesium dan backpropagation gaussian, bisa dilihat bahwa trapesium $m f$ lebih akurat dibandingkan gaussian $m f$.

\section{Simpulan dan Saran \\ Simpulan}

Berdasarkan pembahasan yang dilakukan pada Bab sebelumnya, maka dapat disimpulkan beberapa hal sebagai berikut :

1. Sistem Inspeksi Visual Otomatis (AVIS)) dapat diterapkan dengan baik dalam mendeteksi kualitas ubin keramik (ceramic tile), hal ini terbukti dengan hasil data yang diperoleh sudah sesuai dengan tujuan penelitian yaitu tingkat akurasi yang tinggi.

2. Kombinasi model yang digunakan antara teknik pengolahan citra dan kecerdasan buatan dalam hal ini model Adaptive Neural Fuzzy Inference System (ANFIS) sudah dapat memberikan hasil data yang diharapkan.

3. Pengolahan citra dengan menggunakan teknikAdaptive Network Fuzzy Inference System (ANFIS) dapat membedakan ubin keramik yang baik ( G) dan tidak baik (NG)

4. Model inferensi yang digunakan dalam hal ini ANFIS memiliki tingkat akurasi yang baik, hal ini terbukti bahwa model ANFISkhususnya model hybrid memiliki tingkat kesalahan yang kecil yaitu 1.72737E-01 dan untuk tingkat akurasi pengujian datanya mencapai $99 \%$.

\section{Saran}

Dari kesimpulan dan penelitian yang penulis lakukan, saran yang dapat penulis berikan adalah sebagai berikut:

1. Implikasi Penelitian meliputi beberapa aspek :

a. Aspek system, berupa hardware, software dan mekanisme.

b. Aspek Manajerial, berupa organisasi dan prosedur dan sumber daya manusia.

c. Aspek Penelitian lebih lanjut mencakup pengembangan ruang lingkup, pengembangan metoda, pengembangan indikator dan pengembangan unsur yang dipakai. 
2. Rencana Implementasi

Penelitian ini akan di implementasikan yang dapat dijelaskan pada langkah-langkah sebagai berikut:

a. Melakukan peningkatan perbaikan dan efisiensi implementasi pemrograman berdasarkan masukan dan penilaian pada saat sidang tesis.

b. Pemasangan Aplikasi prototype versi alpha agar dapat digunakan oleh perusahaan

c. Menerima laporan adanya bug dan error pada aplikasi dari perusahaan tersebut, serta akan dikembangkan untuk pengguna lainya.

d. Memperbaiki bug dan error pada aplikasi berdasarkan laporan yang diterima.

e. Mengulangi langkah 2,3,4 hingga aplikasi stabil dan siap pakai.

f. Melakukan sosialisasi terkait dengan aplikasi yang telah dibuat

g. Operasional penggunaan aplikasi dan dokumentasi.

\section{Daftar Pustaka}

A. Fanni, M.Lera, et.al. (2010). Neuro Network Diagnosis for Visual Inspection in Printed

Circuit Boards. DIEE Dipartimento di Ingegneria Elettrica ed Elettronica, Universita' di Cagliari Piazza d'armi 09123 Cagliari, Italy.

Fernando de Aguiar Faria, et.al. (2009). Machine Vision And Artificial Neuro Networks For Seam Tracking And Weld Inspection. ABCM Symposium Series in Mechatronics, Vol. 4. 768-775.

G.Acciani, G. Brunetti, et.al. (2006). Multiple Neuro Network System to Classify Solder Joints on Integrated Circuits. International Journal of Computational Intelligence Research, Vol.2 No.4 Tahun 2006. 337-348. ISSN 0973-1873

Kusuma Dewi. (2008). Artificial Intelligence. Yogyakarta: Graha Ilmu

Ms. Anuja Bujurge, et.al. (2011). ANFIS Based Color Image Segmentation for Extraction of Salient Features: A Design Approach. Int. J. on Recent Trends in Engineering \& Technology, Vol. 05 No. 01 Tahun 2011. 